\title{
Odontologia e Serviços Públicos
}

\author{
Charley Fayal de Lyra \\ C. Dentista do D.A.S.P. Livre Docente de \\ Técnica Odontológica da Faculdade Nacional \\ de Odontologia da Universidade do Brasil.
}

A

Odontologia, quer como ciência ou arte, é uma realidade. Os estudos científicos, os congressos, as associações de classe, e principalmente a intima relação que vem tendo com a Medicina, colocaram-na no conceito certo, exigindo do profissional conhécimentos amplos sôbre a anatomia, fisiologia, radiografia, cirurgia, patologia, clínica, etc., que fazem parte do curso normal das nossas Faculdades, tornando-o um especialista que é, na parte relativa à bôca e tecidos vizinhos, tão importantes na saúde geral da humanidade.

A Odontologia está intimamente ligada à Medicina. O diagnóstico precoce do câncer, tem no Dentista, um dos mais valiosos colaboradores. A pesquisa de focos, o descobrimento de tumores benignos e malignos na mandibula e maxilares, a presença de sinusites, etc., são contribuições de máxima importância dos Odontologistas para os Médicos, e são realizadas como matéria de rotina, principalmente devido ao constante manuseio das radiografias intra e extra-orais, exigidas pela técnica correta dos métodos modernos de se praticar a Odontologia.

Lévando em conta, a importância da ciência Odontológica, o Govêrno, teve a oportunidade de criar em quase todos os setores administrativos, cliniças, que já prestaram e continuam a prestar serviços inestimáveis aos servidores e seus familiares. A necessidade da Odontologia no serviço público não é mais matéria de controvérsias, sendo estudadas, apenas, as possibilidades de ampliação de todos os consultórios existentes. A aquisição de novos gabinetes, devidamente instalados, com anexos para radiografias dentárias e laboratórios de prótese é uma necessidade real para beneficio dos funcionários de tôdas as repartições.

Vários relatórios nos mostram um atendimento enorme de pacientes, demonstrando a verdadeira eficiência e abnegação por parte dos profissionais. Como exemplo do movimento existente nos gabinetes dentários, poderemos mostrar dados referentes ao trabalho executado pelo Serviço de Assistência Social do Departamento Administrativo do Serviço Público, onde com um consultório devidamente instalado, foram atendidos em 1958, uma média te 18 pacientes diàriamente, perfazendo um total de 4.224 . 
NUMERO DE SERVIDORES DENTISTAS NO S. P. F. E SUA DISTRIBUIÇÃO SEGUNDO AS UNIDADES ADMINISTRATIVAS, PADRÕES E REFERÊNCIAS

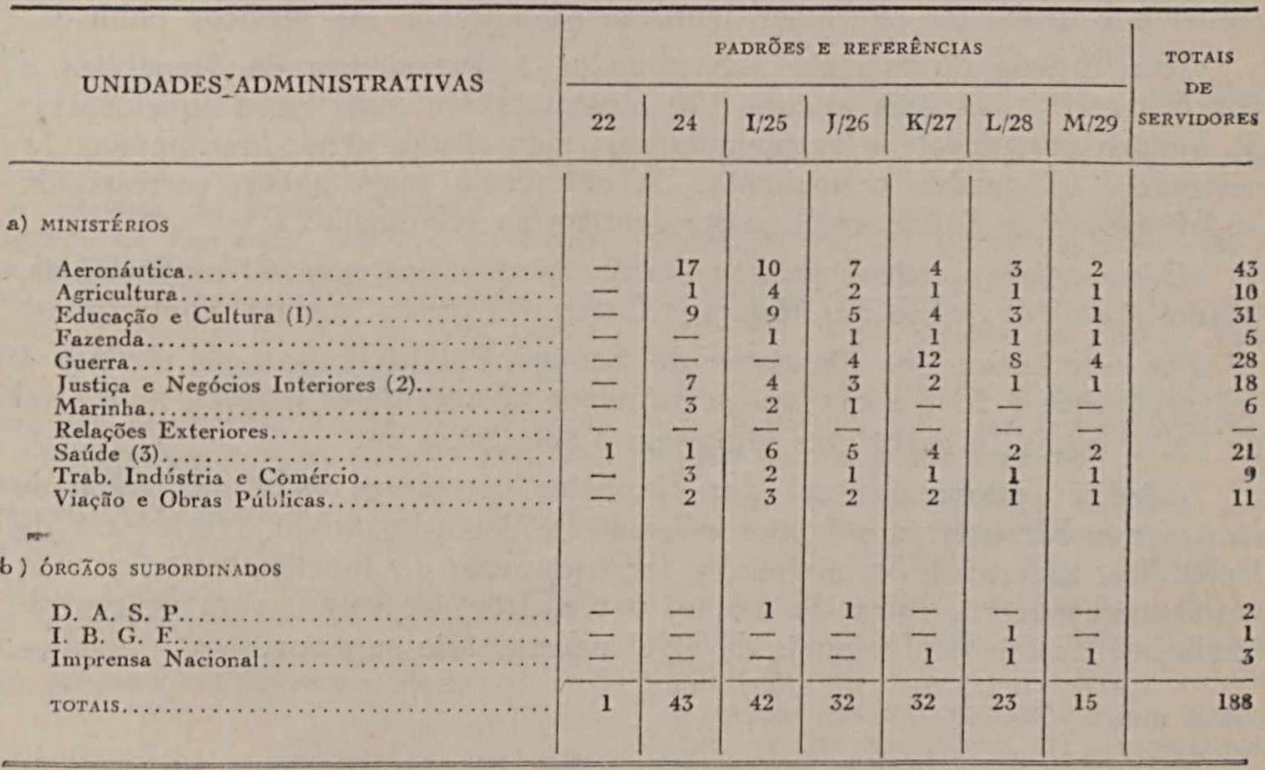

Observações - Inclusive
(1) 2 Servidores $(1 \in K)$
(2) 1 Servidor (I)
(3) 7 Servidores I (2), J (2), K (1), L (1) e M (1).

Os trabalhos executados foram :

\begin{tabular}{|c|c|}
\hline (1) & 270 \\
\hline Curativos $\ldots . .$. & 2.345 \\
\hline Radiografias ... & 1.200 \\
\hline Tratamento de canais ...... & 155 \\
\hline Obturações de canais $\ldots \ldots \ldots \ldots \ldots \ldots \ldots \ldots$. & \\
\hline Tratamento de gengivites $\ldots \ldots \ldots \ldots \ldots \ldots \ldots \ldots \ldots \ldots$ & 273 \\
\hline 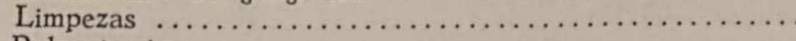 & 236 \\
\hline 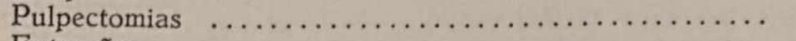 & 9 \\
\hline 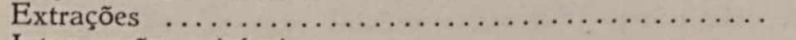 & 12 \\
\hline 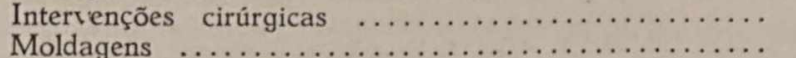 & \\
\hline 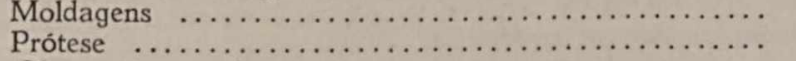 & \\
\hline 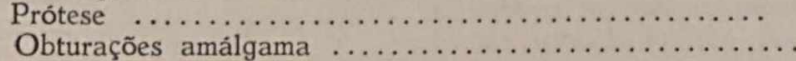 & 4 \\
\hline 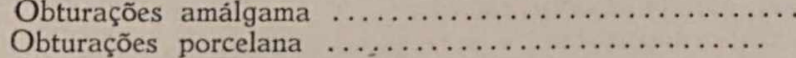 & 47 $-2>$ \\
\hline 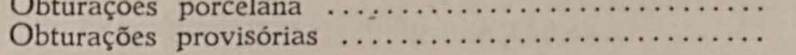 & 320 \\
\hline dos tra & 7.152 \\
\hline
\end{tabular}

Êsse é o movimento de apenas um gabinete dentário, dentre os vários existentes nos serviços públicos.

No Brasil, temos 31 cursos de Odontologia, com 600 professôres e cêrca de 5.000 alunos matriculados. O Anuário Estatístico do Brasil de 1958 nos dá a existência de 19.585 cirurgiões dentistas em todo o nosso 
território. No Distrito Federal até o ano de 1957, o Serviço de Fiscalização da Medicina apresentava o registro de 1.060 profissionais. No entanto é reduzido o grupo de cirurgióes-dentistas pertencentes os serviços públicos.

Nos órgãos diretamente subordinados à Presidência da República e nos Ministérios, existem apenas 190 cirurgiões-dentistas, entre funcionários do quadro permanente e extranumerários mensalistas, sendo que apenas 11 pertencem ao quadro permanente. A referência mais baixa corresponde ao Ministério da Saúde, onde existe dentista na referência 22.

O maior quadro de Dentistas é o da Aeronáutica, com 43 profissionais, sendo que o Ministério das Relações Exteriores possui, apenas, contratados.

As referências dos Dentistas do Serviço Público variam da 22 até a 29 , sendo que a 24 é a que apresenta maior número de ocupantes, num total de 44. Apenas 14 servidores atingiram a referência 29.

Êsse é panorama atual dos Dentistas servidores públicos, ocupando cargos nos Ministérios e órgãos diretamente subordinados à Presidência da República, esperando os mésmos, a reestruturação do funcionalismo, quando seroã enquadrados, como de direito, nos padrões previstos, para se equivalerem aos demais profissionais de nível universitário superior. 